AN ADDRESS

ON

\section{THE CAUSATION OF CANCEROUS AND} OTHER NEW GROWTHS.

\section{Delivered before the Yale University Medical Alumni Association, New Haven, Conn.}

By J. GEORGE ADAMI, M.A., M.D., F.R.S.E. Professor of Pathology, McGill University, Montreal.

Just as to the bright spirits of the sixteenth century, in the expansion and enthusiasm of the time, everything seemed possible and men dreamt of the perfect commonwealth, so to us in this age of medioal renaissance the discoveries that have been made in connection with the causation and modes of prevention of so many important diseases appear to point to the time when the most dread scourges of humanity shall one after the other be subjugated, and our race rise to a level of physical well-being hitherto beyond the bounds of credence. So it is that, regarding the most awe-inspiring and painful of these scourges, cancer and malignant growths in general, while admitting our complete impotence to deal with these conditions save when we have the good fortune to recognise them at their very onset, we nevertheless are not wholly cast down; rather are we sanguine. If we have discovered the cause of so fatal and widespread a condition as tuberculosis, sooner on later we hope to find a speoific cause for cancer. It is, we encourage ourselves, but a question of study and of time. Analogy and the prevailing lhopefulness cause us to expect to find some microbic cause, and, being in this frame of mind, we accept gladly each possible indication pointing to the infectious nature of malignant growths. Already, indeed, we seem to be on the very threshold of discoveries rich in relief to suffering humanity. Discover the cause, say we, and then inevitably we must bring the disease under the roke.

Are we justified in taking this position? Are our studies being directed aright? Are the arguments employed in support of this theory of the infectious origin of malignant neoplasm thoroughly sound? Do the almost innumerable observations which have been made during the last few years bear out the assumption, or have we been neglecting other important factors in the etiology of new growths in the keenness of our desire to determine some specific causative agent?

These are the matters I wish to discuss to-night. The time indeed, is opportune for such discussion when of late, upon this side of the ocean, two well-known surgeons like Roswell Park of Buffalo, and Collins Warren of Boston, have placed themselves in evidence as favouring the theory of infectious - origin, and when, on the other side, a Cancer Number of that well-known journal, the Praotitioner, with its series of articles by responsible writers dealing with different phases of the subject, most assuredly leads up to the conelusion that oancer is an infectious disease.

The Parasitic Theory.

It will be well, in the first place, to adduce the main arguments in favour of the parasitic origin and infectious nature of malignant growths. These, stated briefly and impartially, are the following:

1. That the increase in frequency in malignant tumours in civilised communities during the last four decades is wholly out of proportion to the possible action of any factor, save the gradual spread of some infective agent. It is in excess of any lessening of the death-rate, and not to be accounted for merely by the increased longevity of civilised races-is not, that is, to be explained by the fact that a larger number of individuals now reach the cancer age. The increase is to be seen in country as well as in urban districts, in European as well as in American communities, and cannot therefore be attributed to any one alteration in the mode of life, to altered habits, altered environmont. There is no other common factor capable of explaining the increase, hence, per exclusionem, we must fall back upon infection.

2. That the incidence of the disease is frequently found to 4 be peculiarly localised-certain districts, mainly low-lying, are seen to be especially affected, certain villages and even certain houses in those villages-and this apart from blood relationship between the affected individuals. The incidence is, if I may so express it, of a miasmatic type, resembling, for example, that of malaria.

3. That the lesions produced by the growth of malignant tumours within the organism are comparable with those induced by certain known intective agencies, and that a close analogy can be drawn between the tubercle and the dissemination of tuberculosis, and the primary cancer nodule and the metastatic cancers or sarcomatous growths. Just as in chronic affections there are, as a rule, single primary foci of origin, so with the malignant neoplasms; and just as there is extension of the tuberculous process by continuity (with tlie destruction of the surrounding tissues and their replacement by new tissue), by the lymphatics, or by the blood stream, so it is in connection with neoplasms and their progressive development in the organisms.

4. That the more earefully material from malignant tumours is examined the larger is the proportion of cases in which certain intracellular and extracellular bodies are to be recognised. The series of forms seen, while large, is, according to each individual observer, remarkably constant and not to be regarded as indicative of cell degeneration, though observers differ between themselves as to the specific series of forms. It is generally agreed that these bodies are most numerous in the young growing edge of the tumours rather than in the older central cells in which degeneration might be expected to show itself. While but a few years ago the observations of Sjöbring, Ruffer, Metchnikoff, and others led to these bodies being regarded as parasitic sporozoa and so as being of animal nature, among upholders of the parasitic theory the trend of opinion at the present time, following Russell, Roncali, and Sanfelice, is to regard them as of vegetable origin-as blastomycetes or yeast-like growths. But within the last few weeks there have been indications that the sporozoon theory is again being actively supported.

5. While the cases on record of apparent direct infection from one individual to another are so few as to be explained by the law of chance and as being but the coincidental occurrence of the same disease in two associated individuals, and while the experimental inoculation of fresh canoer material from one individual to the other (whether these be of the same or of lifferent species) has almost uniformly failed, nevertheless, in rare cases, this would have appeared to have succereded; and, according to Sanfelice, the inoculation of a pure culture of a yeast isolated by him has, in a small proportion of cases, led to the production of definite neoplasms. Two factors are necessary for successful experimental inoculation-the virulence of the parasiteand the susceptibility of the tissues-and it may well be that if malignant growths are brought about by parasites of a very low state of virulence, a very special susceptibility or special condition of the tissues is necessary for the inoculation to be successful. To this lack of special susceptibility of the tissues is to be attributed the frequent failure of experimental inoculation, either with cancerous material direct, or with pure cultures grown outside the body.

These, I take it, are the main arguments in favour of the parasitic origin and infectious nature of malignant growths. Stated thus, they present a very strong prima facie case in favour of the parasitic theory. There is, however, I need scarcely say, another side to the question, and each of the above arguments in turn may be, and has been, strongly assailed.

Some capable observers still hold that increased longevity is capable of explaining the increase. A fuller study of lowlying and estuarial regions shows that while cancer is very common in some, it is equally uncommon in others. The analogy between the mode of dissemination of tuberculosis for example, and the development of metastatic cancerous nodules is recognised by all histologists as being thoroughly unsound. Further, it is difficult to refute the careful observations of Fabre-Domergue and of Pianese, that the so-called cancer bodies of varying types deseribed by different observers, are so many different forms of degeneration products within the cancer cells. When by employing special staining methods which afford a differential stain for mucoid, pseudo[2098] 
mucoid, hyaline, and amyloid material, it can be shown that a succession of forms can be made out, passing imperceptibly from conditions within the cells which cannot possibly represent the stages in the life-history of some intracellular parasite to others which the parasitologists regard as indicating stages in the life-history of one or other microbic form-the histological evidence that cancer is due to parasites becomes, to say the least, singularly frail.

I shall not, however, now take up these various arguments and endeavour to weigh their value; rather I would attempt to approach the matter from a different point of view, would seek to determine the relationship of malignant to other forms of growth in the organism, and from a study of this relationship would endeavour to determine whether we are justified in holding this advanced view in regard to the parasitic origin of malignant growths.

\section{Tumours Benign and Malign.}

I would in the first place ask: Can we draw a line between tumours which are essentially benign and tumours essentially malignant? The answer to this question is an unhesitating "No." If we understand by malignancy the property of local invasion of surrounding tissues together with that of the formation of new growths of like nature in distant organs - the other associated properties being subsidiary to these two-then all growths which we classify as true tumours may take on malignant properties. Even so highly differentiated and (ordinarily) benign a neoplasm as the chondroma may exhibit metastases. It is true that very often the assumption of malignant properties indicates and follows a change in the morphological characters of the tumour or parts of the same. Thus the lipoma, as such, is not malignant, but portions of a lipoma may take on a more embryonic character, and the rapidly growing simpler cell forms may infiltrate surrounding tissues and may lead to metastases. Nevertheless, we have no doubt that this sarcomatous tissue is the direct outcome of the cells forming the primary lipoma. There is no question that here the lipoma has taken on malignant characters. It can scarcely be questioned, alsu, that malignancy is not a primary but a superadded property of the tumour, that growth up to a certain point is of the benign type. Hence, if any theory of the parasitic causation of tumours is to conform to the facts already acquired by us as to the life-history of tumours, that theory must assume one of three forms, namely :

I. That all true tumours, benign as well as malignant, are of parasitic causation.

2. That infection is but one of a series of causes of tumour growth, both benign and malignant.

3. That while tumours, as such, need not primarily be of micro-parasitic origin, the assumption of malignant properties is due to infection by parasites, these leading to that active and excessive purposeless cell growth which is the basis of malignancy.

Let us consider now these possibilities. Are all tumours, benign as well as malignant, of parasitic origin ?

\section{Definition of the Term "Tumour."}

Before seeking to answer this question it is necessary to lay down a definition of this term "true tumour." This in itself is no easy matter, for into that definition for our present purposes-and, I may add, equally for general purposes -no definite statement as to causation should be admitted. So long as we are uncertain as to the causation of these growths our definition must be strictly confined to facts. Ziegler's statement that "a tumour is a new formation of tissue possessing atypical structure, not exercising any function of service to the body, and presenting no typical limit of growth," is, on the whole, adequate, though in the existence of such forms as certain adenomata, osteomata, and chondromata the use of the term "atypical structure" requires a little explanation.

I prefer the definition of C. P. White: "A tumour proper is a mass of cell tissues or organs resembling those normally present, but arranged atypically. It grows at the expense of the organism without at the same time subserving any useful function."

Limitations of the Parasitic Theory.

Accepting this as our definition-and I may say that other attempted definitions agree in including or tending to include the same provisions-then immediately we are compelled to recognise that all true tumours are not of parasitic origin. There is the group of teratomata, due to the inclusion within the tissues of one individual of tissues derived from another. These tissues become organically connected with those of the host, and grow at the expense of the host, throughout subserving no function of use to that host. They form a wellrecognised group which'I need not here describe more fully.

Thus, then, on the one hand there are tumours which assuredly are not of parasitic origin, but on the other hand we cannot go to the opposite extreme and say that no tumours are due to the action of parasites in the tissues. It may be laid down that physical and toxic agencies when acting below the point necessary to induce cell exhaustion and cell destruction may act as stimuli rather than as irritants, and doing this may bring about increased cell proliferation. It may be-it has been-argued that these bacteria and their products are not the direct cause of the proliferation. Weigert and his pupils, for example, strenuously deny the direct action, but the fact remains that the bacterial toxins are the initiating, indeed the essential, cause; and the recent studies by Mallory, more especially upon the changes occurring in the endothelium of vessels and lymphaties during typhoid and other infectious disease, seem to prove this with absolute clearness.

Bacterial toxins, which when concentrated lead to excessive cell necrosis, in a less concentrated condition may induce active cell growth. In the central portion of the abscess, where there are abundant bacteria and their products, there is abundant evidence of cell necrosis. At the periphery, where by sundry mechanisms the bacteria are hindered from existing, and where the toxins diffusing out are less concentrated, there is evidence of active mitosis and cell growth.

All the tissue components, it is true, are not alike in their reaction. The simplest forms of cells may be stimulated to proliferate by substances which destroy or arrest the activity of the higher cells in the game neighbourhood. Thus it is that we can trace various stages of bacterial action from those in which destruction predominates to those in which, as in the infective granulomata, the higher tissue elements undergo destruction, but endothelial and connective tissue elements show, it may be in the very earliest stages of the process, well-marked proliferation.

Further than this it would seem that we cannot advance with the bacteria. In other words, so far as our present knowledge permits us to conclude, bacteria-schizomycetes-below a certain degree of toxicity of their products, cannot maintain an existence in the tissues of animals. They succumb to the antibacterial mechanisms of the organism, and succumbing, any proliferative activity they may have induced comes to an end. In plants it is true, we meet with definite bacteria living a symbiotic existence in the rootlets and causing wellmarked overgrowths. It may eventually be found that bacteria are capable of initiating progressive cell growth in the higher animals, but of this power proof is so far wanting.

There are, however, other forms of life which, while of peculiarly low toxicity, are capable of existing and actively proliferating within the tissues of animals. Coccidia, for example, are peculiarly common in the rabbit, but the irritation they set up in the tissues is of so mild a type that in many regions the majority of rabbits, young and old, show the results of their presenoe in the tissues, and that without any sign of disturbance of general health. I need scarcely say that the evidence of their action is especially found in the liver, where, growing within the cells lining the bile ducts, they lead to a proliferation of the same with surrounding overgrowth of the connective tissue, and so give rise to what are truly " oyst-adenomata." Similar growths of like causation have in rare instances been found in the human liver. It is to be noted that the growths so produced are benign and not malignant. For some reason-what reason remains confossedly problematical-the irritation and the reaction to the growth of these microbes is not sufficient to bring about such an active proliferation and continued vitality on the part of the cells that, carried to other regions, these cells reproduce the primary growth. 
The nematode worm, bilharzia, an organism vastly higher in the scale of animal life and one infesting a very large section of the human race, may exist within the organism for long years without setting up any very serious disturbance ; but in those parts of the body which by preference it infests it is clearly capable of producing cell proliferation of an adenomatous, papillomatous, or even of a cancerous type. Living in the radicles of the portal and pelvic vessels, its abundant ova make their way mechanically (on account of their shape) through the vessel walls into the submucosa and mucosa of the lower bowel and the bladder and so into the lumen of the intestines and the bladder respectively. Numerous cases are on record of extensive neoplasms of the rectum and bladder which are clearly secondary to the continued cell irritation induced by these ova. All, $\mathbf{r}$ think, are nowadays prepared, from such cases as these, to agree that there are parasitic agents capable of inducing tumour growth of a benign type; and what is more, that this growth does not merely occur in cells which are congenitally displaced, but in those which, prior to irritation, have been portions of strictly normal tissues.

It would appear, therefore, that the evidence at present in our possession confirms the second possible theory that parasites are but one of the series of causes of tumour growth.

Now, between these two extremes-forms assuredly due to independent cell growth without microbic intervention, and forms assuredly initiated by microbic invention-we have a very broad debatable territory wherein we encounter the main mass of neoplasms. How are we to regard these? Do they belong to the one or to the other class.

\section{Classification of Tumours.}

It will be well in the first place to attempt a rapid classification of the different forms, according to the tissues implicated; according, that is, to the tissues and the cells which give origin to the different forms of tumours. Such a classification is possible. To attempt to indicate the class to which each individual tumour belongs would immediately involve us in a long and, for present purposes, absolutely fruitless discussion. And this, it would seem, very largely because a tumour of one histological type may be produed under different conditions. Carcinoma, for example, may develop in connection with the functionless or relatively functionless cells of the ovarian dermoid; or, again, may originate from the active and functional cells of, say, the gall bladder or the splenic flexure of the colon.

The following classification appears to me to include every form even if this be the case, and even if at the present time we may differ as to the class in which certain varieties of tumours should be placed.

\section{A. Teratomata.}

Tumours composed of the products of growth of one individual within the tissues of another individual of the same species.

I. Teratomata of the first order-Twin Teratomata. Tumours due to the continued growth, within the tissues of one individual, of the tissues and organs of another individual which has become included in the former during fœetal life.

II. Teratomata of the second order-Filial Teratomata. Tumours due to the continued growth, within the tissues of one individual, of tissues and organs which are the product of growth of one of the germ cells of that individual.

(i) Parthenogenetic.-Tumours formed of the products of the unfertilised germ cell. The more recent studies of Répin and Arnsperger most strongly support the view that ovarian and testicular dermoids can only be regarded as examples of abortive parthenogenesis.

(ii) Gamogenetic,-Tumours formed of the products of the fertilised germ cell. The recent work of $H$. Peters has settled the angry discussion as to the nature of the syncytial cells of the placenta; they are, as many have long held, of foetal origin, derived from the outer layer of the fœtal epiblast. They have, physiologically, well marked powers of eroding or breaking down the uterine tissue and through their agency it is that the villi penetrate into the maternal blood sinuses. Physiologically, that is, they possess what we regard as malignant properties. The highly malignant tumour, formed as a result of their overgrowth, the so-called deciduoma or syncytioma malignum. is thus clearly an example of cells individual. Placental moulds belong also to this class.

\section{B. BLASTOMata.}

Tumours composed of the products of aberrant growth of cells and tissues of the individual in whom they develop.

I In which abnormal cell relationship precedes the neoplasia by a definite interval, and apparently predisposes to the aberrant purposeless growth. These abnormal relationships may be $(a)$ inherited, (b) acquired, and then either of ante-natal or post-natal acquire nent.

(i) Heterochronic.-Tumours in which the primary abnormal cell relationship is due to the persistence of tissues from a previous stage of development, which tissues normally undergo atrophy and disappear, Examples: Tumours deve (ii) Heterotopic. -In which the abnormal cell relationship is due to the
displacement of cells and tissues during the process of growth so that the displacement of cells and tissues during the process of growth, so that the thyroids and other tumours developing in accessory glands, rhabdomyomata and suprarenal tumours of the kidney. etc.

(iii) Heterotrophic.-Tumours in which the abnormal cell relationship is due to unequal growth of different elements composing a tissue. Examples: Congenital angiomata and lymplangionata, in which from obstruction or other cause the vascular elements of the tissue become unduly prominent, while the parenchyma is imperfectly developed.

II-Tumours in which one and the same agency leads to abnormal cell ro lationship and to tumour growth.

(i) Tumours in which no primary disturbance of cell relationship is to be recognised, the growth originating apparently from functional cells and tissues, and in which so far the causative agent has not been determined. This group would seem to include a very large number of malignant growths-epitheliomata of the skin, tongue, etc., carcinomata of the stomach, colon, and so on. The more we study the early stages of cancers the more it is impressed upon us that these would seem frequently (though by no means necessarily always) to develop from the cells of tissues that are or that have been normal and functional

(ii) Tumours originating from normal and functional tissues through known microbic agency-for example, coccidiosis of the liver of the abbit, bilharzia tumours of the bladder and rectum

Reviewing the various classes of tumours here rapidly set in order, we recognise a series with at the one extreme tumours originating in misplaced tissue and growing and continuing to grow without microbic irritation, and at the other extreme tumours originating in normal tissues and growing as a consequence of the low form of irritation induced by parasites. Between these two extremes some approximate and apparently belong to the former group, others show evidences of relationship to the latter.

Accepting this as the case it must next be asked, Can we determine anything in common-a common denominator as it were-associating these various groups? Structurally tumours belonging to the two extremes may be of like nature and histological character, and common denominator there must be, and if we can only determine it, then we can proceed to establish the true theory of tumour formation.

I need not say that there have been many attempts to form such an adequate theory, from that of Cohnheim, who, ignorant of the existence of the one group, sought to ascribe everything to cell "rests," to those of present-day writers, who, heedless of the existence of the other group, seek to ascribe everything to microbes. Neither extreme, as I have shown, is possible. I trust that I shall be forgiven if neglecting, on account of the demands of time, to put before you what I may term intermediate theories in full detail, of which those most discussed pro and con. at the present time are the theories of Ribbert and Hansemann, I here give rein to my own line of thought.

Let me in the first place put before you in concise language the problem that has to be solved: (1) Certain tumours arise from misplaced cells; (2) certain tumours arise from cells originally in normal position. What is the cause of either category of cells taking on excessive growth independent of the needs of the organism?

\section{The Relation of Growth and Functional Activity} of Cells.

To solve this problem it is clear that in the first place we must have right ideas as to the nature of cell growth and proliferation in ordinary. Now, as I pointed out a few months ago (in the Jacobi Festschrift) we are apt to have a vague idea, to say the least, of the nature of the normal growth of tissues. The more one studies what occurs in the various tissues, the more obvious it is that multiplication and the active performanoe of other function by the cell are incompatible, or otherwise, that the actively-functioning and fully-developed cell, as such, does not undergo mitosis and show evidences of multiplication.

In not a few tissues (the epidermis, periosteum, etc.) there are present what may be termed proliferous or " mother cells"- cells which themselves throughout life do not attain full differentiation, but which give off daughter cells and the daughter cells it is which develop into the fully-differentiated functional cells. In other tissues the fully-differentiated 
cells are capable of division and proliferation, but this only after reversion to a simpler type, or, as we term it, a more embryonic state, in which evidently their functional secretory activity is reduced to a minimum. Thus after the injection of indigo-carmine, Martinotti has pointed out that in a kidney, portions of which have been removed in order to study the compensatory overgrowth of the remaining part, all the cells of the convoluted tubules in the remaining part, take up the pigment save and except those in a condition of active mitosis : these remain perfectly colourless. Even in so simple a tissue as connective tissue, the cells exhibit this return to a more "embryonic" state prior to multiplication.*

Professor Carlier, of Birmingham, has, I may add, noted eases apparently contrary to what is here stated; cells of the gastric glands may show mitosis and the appearance of secretory granules in their protoplasm at one and the same time. But these may well be stored-up granules. In a letter to me-which in consequence of the long time it would take to gain his necessary permission, I trust I may be permitted to quote-he states that in his opinion a dividing cell may be functionally active. He adds, however, that when this is the case, he is inclined to believe that the nuclear changes characteristic of mitosis become suspended for the time being.

Thanks,to the researches of Hodge, Mann, and other neurologists, of Macallum of Toronto, and of his pupils, Scott and Bensley, and of Carlier, and of other physiologists and cytologists, we are recognising more and more that the nucleus plays a controlling part, not merely in cell division, but also in the function of the cell. With activity, the nuclear chromatin becomes used up and discharged into the body of the aell, there to combine with other substances to build up prezymogens and other bodies, which are eventually discharged as the specific secretion of the cell. This being the case we can readily understand that the higher specific functions of the cell cannot be carried on by a nucleus whose nuclear material is being utilised to its fullest in mitosis. The process of cell division, and the performance of the higher functions of the cell, are incompatible, and the cell engaged in the active performance of its special functions cannot undergo division.

Yet, paradoxically, under normal conditions after birth, it is the ar.tively functioning tissue that undergoes hyperplasia and takes on increased growth. This is to be explained in most cases by the fact that the new units of that tissue are derived, not from the actively functioning cells, but from mother cells present therein ; in other cases, probably by the fact that such hyperplasia occurs where the activity is not continuous, but interrupted, growth occurring in the intervening periods of rest. One may quote, for example, the late Sir James Paget's well-known illustration of the growth of a c srn on the foot being due to an interrupted irritation of the skin by the pressure of a tight boot, that irritation which otherwise would lead, if continued, to atrophy, being removed at night, leads to hyperplasia of the epidermis.

For a cell to divide actively there must be at least temporary arrest of the specific, as distinct from the vegetative, functions. Or, conversely, arrest or disturbance of the specific functions of the cell, if of such a nature as not to arrest vegetative activity, favours cell multiplication. The nuclear activities, unemployed in one direction, become diverted into another; the nuclear material, not being discharged and converted into the specific secretions of the cell, tends to become heaped up, and, accumulating up to a certain point, is then used in mitotic processes.

Influence of Environment on Cell Activity.

While heredity surely plays an important part in deter-

* Here let me urge that the use of this term "embryonic" as applied to cells in an adult organism is of questionable value, and indeed is responsible for not a little of the want of comprehension of the phenomena of normal and abnormal cell "growth. I, would suggest in preference the employment of the term " vegetative" or "proliferous," to include the whole series of these cells. For, strictly speaking, in these cases of reversion to a simpler state, it is a misnomer to speak of adult cells becoming embryonic, and a continuance of or reversion to this simpler histological condition is not an indication of an embryonic condition, but is essentially correlated: to the mode of activity of the cell; or, otherwise, the so-called embryonic cell is a cell which specially is in a position to proliferate, and is not in a position to perform specialised function. mining the structure of the cell, we are forced to see that, underlying and determining heredity, the eventual structure as again the specific functions of a cell, are determined by the sum of the forces acting upon that cell; structure and function are adaptations to environment. It is not only the nutritive material absorbed by the cell that determines the characters thereof, but its position relative to other cells in the economy. From the first the cell continues to proliferate until the sum of the above-mentioned forces brings it sooner or later to a condition of equilibrium, until the amount of nutrition absorbed (and the resultant energy) are fully utilised in maintaining the cell in the status quo. And when this point, is reached, the products of nuclear and cell metabolism, as they are formed, become used up in the performance of function. There is no sufficient surplus or redundancy of material to permit the cells to undergo simultaneously those material transformations which result in cell division. Disturb the environment of the cell, remove certain of the forces acting upon it so that the cell energy previously devoted to counteracting the effects of those forces may now be diverted into and employed in other directions, and thus unemployed energy may be utilised for growth, or perhaps more exactly, the material heaped up by constant assimilation, by its very presence in the nucleus stimulates this to undergo mitotic changes. As a matter of fact, numerous examples can be adduced of overgrowth of tissues due to removal of forces normally acting upon these tissues, overgrowth which continues until such time as the sum of the forces acting upon the newly-formed cells becomes equal to the utilisation of the sum total of the cell energies; then continued growth comes to an end.

This, on the one hand-namely, that removal of forces acting upon the cell from without leads to its passing from the functional to the proliferative state; or, if it be in the proliferative state, leads to its continuing in the same; on the other, increased absorption and utilisation of nutritive material affords the opportunity for increased exhibition of energy, increased katabolism.

\section{Inertia of Cells}

Now increased absorption and assimilation is in general $\mathbf{a}$ response to previous or concurrent increased katabolism and increased activity. So long as this increased assimilation corresponds to and makes up for the loss of substance brought about by this increased activity, for so long is there no tendenoy towards cell multiplication. It, however, may happen that after stimulation the amount of absorption and assimilation may be in excess of the needs of the cell. We have, in short, to recognise the existence of the principle of inertia, recently emphasised in a very suggestive paper by Dr. D. F. Harris

Inertia, physically speaking, is one of the properties of matter in general. Now, just as according to physical terminology there are two kinds of inertia-inertia of matter at rest (or inertia of mass) and the inertia of matter in motion (or momentum)-so in relation to the protoplasm of the cell we notice the same kinds of inertia in evidence. As Dr. Harris points out, protoplasm which is at rest cannot be instantly caused to change that state to respond to stimuli. We have the familiar latent period, and numerous examples can be given of that functional inertia which corresponds with the inertia of movement (momentum), "the inertia that makes the wheel rotate long after you have ceased to spin it." The isolated heart of the frog will continue to beat long after its removal from the body. Hairs continue to grow after the death of the body ; indeed, all cases of organs and tissues continuing to perform functions after their blood supply has been cut off are cases of functional inertia.

And coming now to the immediate problem before us, it may be said that active katabolism, with the active performance of function, leads to corresponding increased anabolism, and that if by nervous or other mechanism the performance of function be arrested, the absorption of nutrition and assimilative processes may still continue for a time. If there be continued access of nutriment this, according to the above principle, is liable to continue over and above the needs of the cell. In other words, there is a liability for reserve material to be heaped up in the nucleus and body of the cell. It is, I would suggest, under these conditions that prolifera- 
tion may replace functional activity. If the cell be not called upon to perform its normal functions, be not called upon to work after previous stimulation has led to increased absorption and anabolism, that cell is in a favourable condition to divert its energies from function to proliferation.

In this connection I would point out that we are forced to recognise that the stimulus for the performance of speeial function is not intrinsic: it does not arise within the cell but comes from without. Vegetative functions, on the other hand, including cell division, would seem to be of intrinsic origin and automatic, determined only indirectly by external conditions, directly by conditions within the cell. The normal cell, in short, stands in very much the same relationship to the organism as does the normal citizen to the body politic; the work that individual performs is determined by his position in the body politic, and is for the benefit of society at large, but at the same time the individual citizen works for himself and for the continuance of his species. The one it is true depends upon and is intimately connected at every point with the other function of the individual, but these two functions of citizenship and self-preservation are clearly distinct, the one determined by external conditions, the other being individual and inherent.

So long as the cell is not called upon to work, and for so long as the surrounding conditions are unaltered, we have the inertia of rest, and so long as the cell leads a purely resting existence, for so long there is no call either for increased activity and breaking down of its tissue, or for subsequent building up in excess of vegetative needs. A cell lying functionless and latent does not therefore show any tendency to proliferate. Alter these surrounding conditions, and a condition of increased metabolism may be induced.

\section{Position of the Cell "Rest" Theory.}

Thus a cell "rest" may remain latent for years or for life, showing little or no signs of growth. The very fact that it is not in a position to perform adequate function is against gowth, so lang as the conditions are unchanged. Change the conditions, and this same fact that it is not in a position to perform adequate function is evidently the reason why the cells forming that "rest" show a peculiar tendency towards proliferation. They are stimulated from without by physical and other means; their relationships to other cells, whether merely of tension or of tension plus position, become altered, and the reactive increased anabolism and storing-up of cell material which cannot be used up in active work to the same extent as oceurs in normally situated cells, is the essential cause why now the stored-up energy becomes utilised in another direction-namely, that of multiplication.*

Here we arrive at the strongest objection to the cell "rest" theory pure and simple of tumour growth. It is one thing to have cell "rests" and fœtal remains present in the variou parts of the body, quite another thing to have tumour growth originating in these. It is probable that the vast majority of cell "rests" never take on an excessive purposeless growth. Cell "rests" may show signs of active proliferation from the first; they may, on the other hand, lie latent for long years, only then showing tendencies to excessive overgrowth ; lastly, they may never be found in other than what I may term "a resting stage." So that, granting the existence of cell "rests," we cannot grant that these misplaced cells are the primary cause of tumour formation-at most they are a predisposing cause; some other cause-a something acting upon the cell "rests"-is necessary to explain their aberrant and excessive growth. We have to demand some ahange in the surrounding conditions.

\footnotetext{
*Along these same lines we best explain the proliferation of mother their relationships lead them to live a vegetative existence. Alteration in their surroundings brought about by increased activity of the surrounding daughter cells must tell upon their relationships, and altered tension and environment must here again lead to the same reactive in creased anabolism, and this must initiate cell division. Where again we have cells once functionally active becoming through senile change latent and somewhat atrophied, here also any stimulus, whethe mechanical, chemical, or physical, acting upon those cells and calling for increased activity, may in like manner render those cells peculiarly liable to proliferate. The change of relationships in the cells brought about by their atrophy and the somewhat altered relationships of the surrounding parts may render them incapable of performing thei normal functions, and increased anabolism may be followed instead by multiplication.
}

Conditions negessary for Cellular Hyperplasia.

Keeping in mind these two conceptions, namely, that the stimulus to increased functional activity comes from without, and that the cell in its actions exhibits marked inertia, we can thus realise the conditions under which increased cell proliferation may be excited in a tissue, whether normal or containing misplaced elements. These conditions are either : (I) That the cells be subjected to periodic irritation leading to increased functional activity, increased secretion, etc. followed by periods of rest in which there is storage of cell material to such an extent that the vegetative activities of the cell are called into play to utilise that material in proliferation; or (2) that the irritation be of such an extent and continued for so long a period, that in consequence of the in creased functional activity of the cell, of the increased secretion, and the increased blood and lymph brought to the part, the relationships of the cell to those in its immediate neighbourhood are altered to such an extent that, while there is adequate or even increased assimilable material which it can absorb, the very alteration of environment and the increased tension to which it is subjected hinders the proper perform ance of function, and the stored-up energy becomes diverted from the performance of specific function to proliferative activity.

Now, considering the first condition, the very property of inertia must be a preventive of sudden change from the functional to the proliferative stage of the cell, while again, the environment of the cells continuing relatively unaltered, they must easily respond to the recurrent stimulation to perform their normal functions, and responding, the tendency to multiply must be liable to arrest. Thus I am inclined to consider that while this condition may be possibly in action to induce that moderate and orderly amount of overgrowth which follows upon increased tissue activity, it is incapable of inducing or explaining neoplasia.

A Starting Point Common to All Forms of Tumour.

It is the second state, or condition, that affords the starting point for excessive local overgrowth in previously normal tissues. And accepting this view we at last reach the position of obtaining one common starting point for all forms of tumour proper. This starting point is that condition in which the cells of the part, whether functional or lying latent, upon being stimulated and as a consequence undertaking active assimilation and anabolism, cannot from their relations carry on their peculiar functions to a corresponding extent, so that the accumulated energy is instead utilised in mitotic changes and cell division, rather than in the normal katabolism.

Herein, however, we do but explain the first stage in the development of a tumour proper. How is it that once started the cells continue to proliferate? What are the conditions under which we can recognise and explain the development of the condition of uncontrolled proliferation? It is clear that at first at least that same stimulus which had led to increased assimilation in the parent cells must continue in evidence, for, if this were not so, then the new cells would either lead but a datent existence, or the tissue in which they are present reverting to a normal state, these cells would gain the same relationships as were possessed previously by their parent and "sister" cells; they would develop into normal functional cells with specialised structure. We are bound, therefore, to assume that this is not the case-that the primary stimulus continues to act for a certain period, and that as a result of this continued action there is developed a colony of cells all tending actively to proliferate. But now the greater the proliferation the more inevitable must it be that a certain number of new cells assume relationships more and more removed from those proper to the parent cells. Some of these new cells, at least, must pass to a greater distance from the blood capillaries and blood supply, from the lymph channels and the terminal nerve supplying the part, and becoming thus still further removed from the ordinary relationships of the cell forming the particular tissue which has given them birth, still less are they capable of performing normal functions; still more, granted zdequate nutrition, are they liable to proliferate. If becoming thus heterotopic their nourishment is cut off, they of necessity die or at least their continued proliferation is arrested. If also the very abundance of the new cells formed leads to marked. 
increase of the pressures acting upon those cell growth is equally arrested.

According therefore to $(a)$ the time of continuance of the primary stimulus (under which term, be it remembered, for the time being I here include everything capable of inducing modified cell relationships to an extent sufficient to permit continued anabolism with perverted katabolism); according also to $(b)$ the relationship assumed by these new cells one to the other; and $(c)$ the tensions to which they are subjected, so do we have or not have the conditions favourable for continued and increasing growth and development of new cells. It is this continuance of the primary stimulus coupled with continued proliferation which gives as the second stage in the evolution of the tumour. These newly proliferated cells may exhibit various departures from the structure and appearance of the fully-formed functional cells, according to the extent in the alteration of their relationships and the extent of the stimulus. Under one order of conditions, inertia and heredity may lead the new cells to assume specific characters very closely approximating those of the parent cells, and the more the cells are of specific functional type the slower will be the growth; under another, the departure from type may be so extensive that it is difficult to deter mine from the individual cells the tissue in which they originated.

Theory of Continuous Tumour Growth.

But even at this point we have not explained tumour formation. We have but reached the stage met with in infective granulomata in which, destroy or inhibit the toxic oause of the cell overgrowth and that overgrowth ceases. We have still to account for the continued automatic growth of tumours proper. . For such, it seems to me, there are two possible explanations. Of these the first and most obvious is that the modified relationship of the parts, or the stimulus which originated the growth in the first place, continues persistently in action. In those cases in whioh, apparently, modified relationships of the cells to each other are sufficient to act as the primary cause of growth, it is not, I think, possible to conceive the continuanoe of the same initial disturbance throughout the life of the tumour; the very growth and massing together of the cells must remove the old and introduce a new series of relationships; we cannot, for example, apply this idea of altered environment alone to explain the production of metastatic growths. It is not merely the outward relationships of the cells, but something in their constitution that can alone explain this active proliferation of cells in regions wholly away from their primary seat of growths, in regions where they are exposed to totally new conditions.

It is, however, quite possible to conceive the continued existence of microbic parasites within the new growth or within the cells of that growth, the products of which by irritating the cells and modifying their functions would continually stimulate the cells to multiply along the lines already laid down. It is possible to conceive these cells and parasites being conveyed to distant parts by the blood or the lymph stream, and when the cells come to rest the associated or symbiotic parasites still by their products affecting the cells in their new relationship, and thereby leading to continued growth. This, I take it, is the usual conception of those who propound the parasitic theories of cancer formation.

But herein comes the difficulty. Continuous purposeless growth is characteristic of all forms of tumours proper; nevertheless, as I have already stated, in a very large group of tumours all the evidence we possess points surely to the fact that microbes have not initiated the growth, and are not concerned in the continuance of the growth.

It would be absurd to urge that microbic agencies play a constant part in the produotion of the group of teratomatous tumours. No one would suggest that such are the cause of post-operative. implantation cysts, of simple congenital dermoids, such as the little hairy dermoids upon the sclerotic, or of the different forms of angiomata. And we can recognise no sharp dividing line, histologically, between the tumours just mentioned and another group including the rest of benign and malignant neoplasms. Histologically all are of the same type.
Further, we can recognise no sharp dividing line between the benign and the malignant forms of such tumours; there is no one stage in which it is possible to say, thus far one set of conditions has been at work leading to purposeless cell growth, beyond this microbic irritation enters in. In both benign and malignant tumours the growth is purposeless, and the only feature separating the two forms is the rate of proliferation and stage in which that occurs. And certainly we encounter every transition between tumours of frankly benign and those of frankly malignant type.

The "Habit of Growth" in Cells.

Here let me be clearly understood. I am not arguing that parasites, intracellular or extracellular, may not be regarded as originating a certain number of tumours; I am pointing out that certain features are common to all tumours; that microbic parasites and the irritation they may induce are not common to all tumours, and that this last factor is therefore inadequate to explain those characteristics which are common to tumours in general. Thus it is that $I$ am led to favour a theory which $I$ believe is applicable to all tumours, whatever their origin. Briefly, this theory is based on the fact that cells and their descendants which for long periods have been subjected to certain influences, whereby their properties and structures have become modified, eventually retain those properties after the influences referred to have ceased to act upon them. I base it again upon that principle of inertia already indicated - a principle which some years ago (1896) in this connection I referred to as the "habit of growth."

Here let me cite oertain examples illustrating the existence of this principle in connection with tumours:

It is a familiar fact that a columnar-celled epithelium, subjected to altered conditions of certain orders, is liable to become converted into a squamous, many-layered epithelium. Such transformation is often noted in the uterus that has been prolapsed and everted; it has been noted in the gall bladder after chronic inflammation, and again in the larynx. What is more-and this is a point to which I would especially call your attention-from the uterine mucosa under these conditions, it has been observed that if cancer develops, it tends not to be of the columnar or adeno-carcinomatous type usual in the uterus, but to be definitely epitheliomatous and of the squamous-celled type. The development of primary epithelioma has been more than once recorded in the gall bladder, and, as there is no squamous epithelium anywhere in the neighbourhood of the normal gall bladder, the generally-accepted conclusion is that there has been a pre-existing ahronic inflammatory condition, which has caused metaplasia of the columnar-celled mucosa into a stratified epithelium. So also where an epithelioma arises in the larynx, away from regions where-as along the edge of the vocal cords-such stratified epithelium is normally present, the most satisfactory conclusion is that a similar metaplasia has preceded the cancerous development.

Now certainly in the first of these cases, and most probably in the others, long-continued irritation and modified conditions of environment have led to a change in structure, and this change has impressed itself upon the affected cells to such an extent that even when these cells take on cancerous proliferation, and their descendants penetrate into the deeper tissues-away from the conditions which affected their progenitors-they still retain well-marked evidences of their acquired characters, and they produce, not a columnar-celled, but a squamous epithelial cancer. I fail to see how such cases can possibly be explained unless we accept this principle of what we may term the inheritance of acquired characters by the individual cells of the organism. Pathologists in general freely accept this as the explanation of the occurrence of primary squamous-celled epitheliomata in the uterus and the gall bladder. Apparently, so far as I have seen, the significance of these tumours, as indicating an important property of the cancer cell, has not been hitherto realised.

It is nowadays almost needless to point out that to explain immunity we are forced to admit a similar well-marked inheritance of acquired characters by various cells of the organism. And so I urge that in connection with cancers and with tumours in general these facts may be applied to the elucidation of tumour growth. When cells have for long been sub- 
jected to those modified conditions under which they multiply actively and rapidly, then, provided the stimulus or cause of this state acts over a sufficiently long time, the cells take on the "habit of growth." They continue to proliferate in a purposeless manner long after the factors which started the process have ceased to act. Their growth and proliferation is no longer inhibited by the performance of specific functional activities; it becomes wholly independent of the needs of the organism, and the more extreme this independence of growth the more the cells lose the signs of their primordial function, the more malignant the growth. Provided that there is adequate nutrition it matters little where these cells find the mthemselves; they grow for themselves. Assimilation and mitosis are the two cell functions retained and impressed upon them. They have cut adrift from the old relationships and tensions which determined the primordial activity of the parent cells. They have reverted from the specialised structure impressed upon them by that primordial activity, as by heredity, until but a trace of that structure is left. They assume the form common to cells undergoing mitosis, a form we term embryonic, and that because this is the form characterising actively proliferating cells in the embryo. This form, let me repeat, is not so much embryonic as proliferous. It is peculiar to actively dividing cells at all times of life.

Whatever the origin, therefore, of the tumour proper, however it is started, what makes the tumour is the assumption by the primary cells of that tumour of the habit of growth in place of the habit of work, and, according to the extent of this replacement, so do we get the various grades of tumour formation from the most. benign to the most malignant.

Summary of Arguments.

Let me now sum up the various points brought forward one after another in arriving at this conclusion. They are:

I. The katabolic activities of the cell are of two orders: those determining the relationship of the cell with the exterior, and those that are vegetative determining the continued existence and multiplication of the cell; the former excited by stimuli of various orders from without, the latter only indirectly so excited, being more directly called into play by conditions obtaining within the cell.

2. The controlling agency in at least the higher katabolic activities of the cell, both "functional " and "vegetative" is the nucleus, and nuclear activity is accompanied by breaking down and discharge, or by rearrangement of the nuclear molecules.

3. The changes which occur in the nucleus during the active performance of the specific functions of the cell are of a character so different from those observed during the process of cell division that proliferation and active performance of specific function, the one precluding the other, are obviously to a large extent incompatible. The cell engaged in the active performance of function in response to external stimulation cannot simultaneously proliferate.

4. It follows therefore that active cell division and cell proliferation occur only in conditions in which the cell cannot fully utilise the assimilated material (and the energy stored up in the assimilation of that material) in the performance of its specific functions.

5. Such conditions are to be met with where the tensions acting on the cell are reduced and certain energies which before were necessary to counteract opposing forces are freed and become thus capable of diversion from their purpose, or again, where stimulation from without results in increased assimilation and storage of nuclear and cell material which now from any condition cannot be utilised in the performance of specific function.

6. In either case the cells will continue to proliferate so long as the primary modification of physical relationships or the primary stimulus oontinues to act, so long as there is adequate nutriment and so long as the tensions exerted upon the cells do not become excessive.

7. Provided that these conditions are observed, the greater the amount of cell proliferation, the greater the tendency for certain at least of the newly-formed cells to be projected from the relations proper to cells of the tissue giving them origin, the less will be the opportunity for such cells to carry on their primordial function, the greater the liability to proliferation.

8. The longer the cells are diverted from their proper extrinsic functions to proliferative activity, the greater the momentum acquired by them to continue performing the proliferative act unit the functional activities become largely suspended and the "habit of growth" is set up.

9. When this habit of growth is inaugurated the cells can continue to grow and multiply in the complete absence of those conditions which initiated their proliferation in the first place, and we obtain that purposeless functionless cell growth characteristic of the true tumour.

Io. According to the stage of cell development in which this habit becomes impressed upon the cell, so do we have the various grades of benign and malignant tumour formation.

Application of Theory.

How now does this theory apply itself to the possible microbic origin of at least certain forms of malignant and other tumours? It applies itself thus: According to this theory, microbes and their products may be one of the causes originating localised cell proliferation in the first place, provided that (I) they bring about stimulation rather than irritation, or irritation of so mild a type that the cells are stimulated to an increased metabolism which does not go on to exhaustion and excessive breaking-down of their protoplasm, provided, also, that the microbes and their products continue in action for a sufficiently long time to set up the habit of growth. It is quite conceivable that such microbes might continue to exist in the tumours they originated, exerting a cumulative effect. The more the cells departed from type the greater the effect of these microbes and their products in producing a tissue of rapidly-proliferative and malignant. type.

This continuance and persistence of microbic action, however, must not, I think, be regarded as essential. The very fact that after all these years and after the hosts of careful observations, we are still in very grave doubt as to whether any of the bodies seen in tumours are really parasites, the fact that no growths of these bodies have surely been obtained outside the organism, and then upon injection have induced tumour formation, although by no means proof absolute, may be quoted in favour of the view that if microbes originate malignant tumours, they do not continue in the living state.

I was not a little interested to note that while Sanfelice was apparently able in his observations to induce the formation of neoplasms in two out of rather a long series of animals, following upon inoculation of these animals with his blastomycete - the saccharomyces neoformans - when he came to make cultures from the tumours and from the other tissues of the animals possessing these developed tumours he was unable to gain any growths. An observation somewhat to the same effect I have come across recorded by Dr. T. Harris, of Manchester, in a case of cancerous growth of the bladder associated with and evidently secondary to bilharzia disease. Harris calls particular attention to the fact that although there were abundant ova of the bilharzia in the surrounding vesical tissue, the tumour itself stood out completely free from any sign of these parasites.

It is quite possible, according to this theory, that certain specific forms of microbic life originate certain forms of tumour growth-of cancer and sarcoma, for example; that, like other pathogenic microbes, these may show a predilection to attack special tissues under special conditions; and if it be true (for some doubt continues to be thrown upon the matter), that malignant growths are specially common in certain localities, then such microbic origin becomes eminently probable.

But if this theory be true, it does not follow that, discovering the causative microbe, we shall be able to arrest the development of cancer by antimicrobic or antitoxic means. At least, in the present state of our knowledge, I fail to see how we can. The most we can look forward to is, on the one hand, the discovery and employment of means whereby to destroy or arrest the continuous growth of cells which have taken on this functionless growth; and, on the other hand, studying their habits outside the body, to exterminate the causative agents, just as nowadays it is being attempted with marked 
success to exterminate the mosquitos in some malarial regions.

I would urge, then, that at the present time, when after all these years of labour no causative agent of malignant growth in general has with certainty been determined, that line of research which promises surer results and greater profit on the part of olinicians as well as of laboratory investigators, lies in the direction of testing various methods of arresting the growth of the tumour cells without injury to the organism in general. Herein it seems to me that Coley has chosen the better part. But over and above all I cannot but feel that the greatest benefit to the patient, the greatest triumph and satisfaction to the practitioner, will for yet some years to come be the recognition and successful removal of malignant tumours at the earliest possible date. Aye, and what is more, the removal of benign tumours in general before they have taken on possible malignant characters.

I wish I could be more optimistic, for optimism is good and healthy, but the above deductions are the necessary outcome of the considerations put before you this evening. As to the theory here put forward, I am quite prepared to find that many will find at first difficulty in grasping it, but when grasped, I cannot but believe most firmly, it will be found to include and to explain the largest number of individual cases -that it will be found to satisfy the conditions of sound theory.

the Habit of GionograpHY On Growth and Overglowth; Festschr. in lionour of Dr. A. Jacobi (New York), May, r900, p. 422, and Med. Chron., Manchester, June, rgoo.
Arnsperger, Virch. Arch., Bd. clvi, 1899, s. r; see also Wilms; Deut. Arch. f. klin. Med., lv, 1895, s. 219: Zeigler's Beitr., xix, 1896, s. 233 and 367. Carlier, BBITISH Medical JouRnal, September rsth, rgoo, p. 740 Hansemann, Die mikroscop. Diagnose der bosartige Geschwulste, Berlin (Hirschwald), r897. Iiaris, D. F.j BRITISH MEDICAL JourNAL, September rsth, rooo, p. 74r. Harris, T., Trans. Path. Soc.,
Condon, vol. Xxxix, p. 183, r888. Hodge, Amer. Journ. of Psychol. iii,
r8go, p. 530: Journ. of Morphol., vii, r892, pp. 99 and $449 ;$ Journ. of r89o, p. 530: Journ. of Morphol., vii, r892, pp. 99 and $449 ;$ Journ. of Physiol., xvii, p. 129, 1894. Loeb, Arch. f Entwickelungsmechanik, v, r897. Lundgren, v. Hektoen's articles in Progressive Medicine, vol.i. Macallum, Exper. Med., ii , 1898, p. 6ri, and Trans. Assoc. Amer. Phys., xv, rgoo, p. 224. Mann, Journ. Anat. (tnd Physiol., Xxix, p. roo, r895. Martinotti, Centralbl. $f$. allg. Path., i, r89o. Park, Roswell, Trans. Amer. Surg. Assoc., xvi, 1898, p. 182. Peters, H., Die Einbettung des monschlichen Eies., Leipzig und tioner, Cancer Number; $\Lambda$ pril, r89. Répin. Origine parthénogénétique des kystes dermö̈des de l'ovaire, These de Paris, 1892. Ribbert, Das pathologische Wachstum der Gewebe, etc., Bonn (Cohen), r8g6. Sanfelice, Centrabl. f. Bakt., Xxiv, 1898, s. I5. Warren, Collins, Boston Med. and Surg. Journ., vol. exliii, r9oo, p. 25. White, C. P., Journ. of Path. and Bacter.,

\section{ON THE OCCURRENCE OF PYREXIA IN CANCER} AND OTHER DISEASES OF THE LIVER, AND IN CASES OF GALL STONE.

By C. O. HAWTHORNE, M.D., M.R.C.P., Physician to the Central London Ophthalmic Hospital ; Assistant-
Physician to the Royal Hospital for Children and Women.

The general attitude to the question of the state of the temperature in cancer of the liver has probably to a large extent been determined, either directly or indirectly, by the statements in Murchison's well-known book on Diseases of the Liver and by the parallel passage in Wunderlich's elaborate work on Medical Thermometry. According to Murchison " in cancer, unless there be some inflammatory complication, the bodily temperature is at or about the normal standard, and accordingly in the case of an obscure internal disease a continuous elevation of the temperature would in itself be opposed to the diagnosis of cancer." He mentions as quite exceptional events two cases which departed from this rule. In one, the average morning record for the six days before death was $99.3^{\circ}$ (maximum Ior. $\mathrm{I}^{\circ}$ ) and the average evening record $101.6^{\circ}$ (maximum $103^{\circ}$ ), this condition of the temperature, together with other circumstances, inclining the diagnosis in the direction of pyæmic inflammation. The second case is simply noted as one of "primary uncomplicated cancer of the liver with a temperature of IO2 $^{\circ}$." Wunderlich's opinion is that "it is a peculiarity of cancer cases that elevated temperatures are comparatively rare and that the temperature generally maintains itself on a normal or subnormal plane, which, however, by no means precludes the occurrence of high temperatures through intercurrent complications or at the close of the disease; but fever temperatures of long duration are at least rare in cancer patients."

Some other authorities may also be quoted on this point. Harley says: "All signs and symptoms of pyrexia are in cases of noncomplicated cancer of the liver totally absent.

Hilton Fagge: "There is sometimes slight pyrexia $\left(100^{\circ}\right.$ or ror ${ }^{\circ}$ and in one case [Pye-Smith] ro4. $6^{\circ}$ ) for which no other cause can be found after death,"

Budd: "When the tumours grow rapidly some degree of fever is set

Frerichs : "Progress however is never completely uniform.......periods during which the tumours grow rapidly, the pains increase and feve shows itself, are followed by others in which the morbid growth is quiescent or retrogrades"; and

Osler; "In all rapidly-growing large neoplasms of the liver there" is more or less fever, usually continuous and not reaching a high grade

With one exception these authorities may be quoted to show that, whatever be the explanation, pyrexia more or less extreme is an event which may undoubtedly appear in the course of a case of hepatic cancer. In reference to the phrase cases of " non-complicated cancer of the liver" which is used by several authorities, it may be remarked that whilst the suggested limitation may be of importance to the issue in an academic discussion, it is of little value from the practical and clinical point of view unless the existence of "complications" can be definitely and confidently determined. And it is notorious that as a matter of fact this is not the case. Not only, as stated above and as will also appear in the sequel, are there cases of cancer with accompanying pyrexia in which no complication can be discovered after death, but it is common to find in the neighbourhood of a cancerous liver inflammatory changes of the existence of which during life there was an entire absence of specific evidence. Further, there is the fact that the occurrence of such inflammatory changes in conditions other than cancer-as, for example, from the irritation due to a longimpacted gall stone-produces in the examination of the patient facts which are the very crux of the physical diagnosis. The problem at the bedside is not, Does cancer pure and simple cause pyrexia? but rather, What is the interpretation of the physical facts in this case, and what bearing has the state of the temperature on the diagnosis If the physician is able to say the case is one of cancer, it is of little practical moment whether he believes any existent pyrexia to be due to "complications," or to be a direct result of the malignant process. There is not in the circumstances just suggested any diagnostic difficulty. Such difficulty arises when-and it is not an exceptional experiencethe physical facts are of doubtful interpretation, and the weight and bearing of the other features of the case, including the state of the temperature, have to be carefully reviewed and estimated.

The clinical question in short is" not, Is the case one of cancer with or without complications:? but, Is the case one of cancer at all? And it is the not infrequent ambiguity of the physical facts in cases of hepatic disease which raises to a level of high importance the study of the value and significance of the symptomatic and general evidence in these cases. Of course if it is true, as it undoubtedly is, that a considerable degree of pyrexia may attend cancer of the liver the clinical distinction of that disease from impacted gal stone, abscess, and other hepatic conditions in which febrile disturbances more or less frequently oocur, is not facilitated. But the recognition of this clinical truth may at least save the physician from an inclination to place undue stress upon the existence of pyrexia as a reason for excluding cancer from the diagnosis.

The facts as to temperature in some cases of cancer of the liver are displayed in the following charts. In Case III there was no necropsy, but in the other instances the diagnosis was confirmed by post-mortem examination.

CASE I. - The patient was a man, aged 48. His illness commenced two months before the date of the chart with " attacks of cold and shivering," after which he became jaundiced; there were no rigors under observation. The physical facts were highly suggestive. Towards the end fluid accumulated in the cavity of the peritoneum and there was odema of the lower limbs. The necropsy showed numerous carcinomatous tumours in the liver. On the surface of one of these was a the peritoneal cavity contained a large quantity of blood, some manifestly recent, some old, which weighed several pounds. The occurrence of hæmorrhage swithin the cavity of the peritoneum is of interest. 